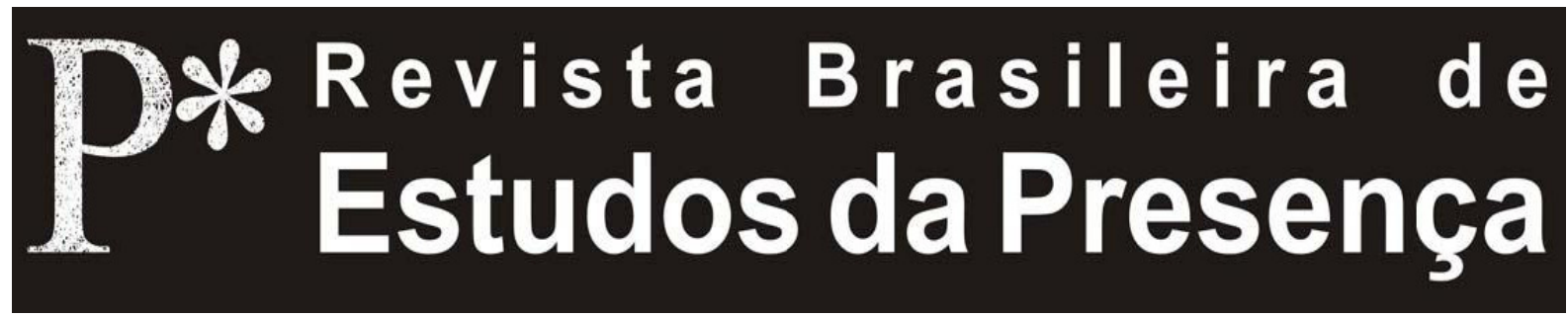

DOI - http://dx.doi.org/10.1590/2237-266036725

ISSN 2237-2660

\title{
Da Via Negativa como Espaço de Travessia: 0 trabalho do ator e sua relação com o Real
}

\author{
Carla Andréa Lima \\ Universidade Federal de Minas Gerais - UFMG, Belo Horizonte, MG, Brasil
}

RESUMO - Da Via Negativa como Espaço de Travessia: o trabalho do ator e sua relaçáo com o Real ${ }^{1}$ - Pretende-se refletir sobre a via negativa, articulando-a com os processos de construção da corporeidade e da subjetividade, com base nas conceituaçóes de corpo, sujeito e inconsciente da teoria psicanalítica, propondo entender o trabalho sobre si como um trabalho sobre o negativo pensado como modo de presença do Real.

Palavras-chave: Via Negativa. Corpo. Formação do Ator. Inconsciente e Psicanálise.

ABSTRACT - Via Negativa as a Crossing Space: actor training and its connection with the Real - We intend to reflect on the "via negativa" linking it to the processes of construction of embodiment and subjectivity, based on concepts of body, individual and the unconscious in psychoanalytic theory, proposing understand the work on the self as a work on negative idealized as kind of presence of the Real.

Keywords: Via Negative. Corporeality. Training of actors. Unconscious and Psychoanalysis.

RESUMÉ - La Via Négative comme Espace de Croisement: le travail de l'acteur et les relations avec le Réel - Cet article propose une réflexion sur la via négative en la mettant en relation avec les processus de construction de la corporéité et de la subjectivité. Fondé sur les notions de corps, sujet et inconscient de la théorie psychanalytique, il cherche à comprendre le travail sur soi à partir d'une approche négative, envisagée en tant que mode de présence du Réel.

Mots-clés: Via Négative. Corporéité. Formation de l'Acteur. Inconscient et Psychanalyse. 


\title{
O Movimento do Desejo e o Trabalho sobre Si
}

\author{
É preciso esquecer? É preciso se lembrar? De quê? Do \\ que não se sabe nomear... \\ Maurice Blanchot
}

"No princípio era o ato, mas - por sorte - era também a palavra", afirma Flazsen ao se referir ao processo grotowskiano. Comecemos entâo pela palavra e interroguemos sobre sua dimensão de escrita, ou melhor, de inscrição de um saber. A hipótese é que o ator, ao fazer do corpo espaço para que a escritura teatral se estabeleça, atesta, em ato, o próprio limite dessa escritura, limite esse engendrado pelo corpo na sua articulaçáo com a pulsão. $\mathrm{O}$ corpo em ato ultrapassa (e muito) o limite do conhecido e do entendimento, se tomarmos como entendimento aquilo que conseguimos organizar de nossa experiência numa rede lógica, causal e sem paradoxos.

Ao pensar essa relação no percurso grotowskiano, Flaszen salienta que o artista a mava repetir que "[...] as palavras e as definiçóes não têm grande importância, que de bom grado poderia substituir uma fórmula ou uma palavra. Porque só a prática, só o ato conta" (Flaszen, 2007, p. 18). Por outro lado, pontua que "[...] a ideia de fixar as próprias experiências na palavra talvez não o tenha jamais abandonado" (Flaszen, 2007, p. 18).

$\mathrm{Na}$ sua tentativa de contornar a experiência, Grotowski parecia reticente com a escrita e com o arcabouço que ela comporta. Poderíamos dizer que o grande receio era o de que as palavras abrissem espaço para equivocidades ou o congelamento do fazer em estereotipias. Ainda segundo Flazsen: "Grotowski-Autor-da-Mensagem-Verbal travava batalhas maníacas de horas e horas para cada palavra" (Flazsen, 2007, p. 18). De modo que: "Apesar daquilo que repetidamente declarou, Grotowski atribuía às palavras uma enorme importância. Como se, de uma certa enunciação no papel impresso, e até mesmo de uma palavra ou de uma fórmula, dependesse o mais alto ser ou não ser" (Flaszen, 2007, p. 19).

O que me interessa prioritariamente com essa breve introdução é pensar justamente a relação que se configura entre o saber (ou seja, aquilo que, passível de ser abarcado em nosso horizonte de experiências e que acaba por constituir um plano de visibilidade, uma escrita, uma inscrição a partir dos quais nos re-conhecemos como sujeitos, construímos metodologias e nos situamos em nossas práticas) e aqui- 
lo que se configura como um corte, uma hiância, um ponto cego marcado pela indiscernibilidade e pela opacidade de nosso desejo ${ }^{2}$ e pelo náo-saber que nos constitui.

Do desejo, sabemos que o fantasma que o sustenta resta incognoscível. Fantasma que se coloca como última amarração para aquilo que, nuclear na estrutura do sujeito e de seu desejo, se apresentará como concretude inacessível, marcada pela alteridade do Outro ${ }^{3}$ que nos constitui. Poderíamos, portanto, dizer do movimento do desejo, que ele se sustenta a partir desse vazio sobre o qual se funda um sujeito e que é a própria potência de seu desejo.

Desse vazio, que não se opóe ao vivo e nem tampouco à potencialidade de um vir-a-ser, pode-se dizer que ele parece cada vez mais alheio à experiência contemporânea que, mergulhada no imediatismo e regida pelo imperativo da felicidade, assim como por uma predisposição permanente a divertir-se e a gozar, acaba por tomá-lo como um simples nada, tangenciando somente seu caráter mortífero. $\mathrm{Na}$ visão de Pierre Fédida, o vazio é fundamental para concebermos o psíquico sendo a escuta analítica algo que se dá exatamente em relação a esse, não para preenchê-lo ou substituir o ausente, mas para fundar uma relação com a ausência (Fédida, 2002).

Sendo assim, o desejo sempre nos apresentará sua face enigmática, nos perguntando "Que queres?". É também por isso que ele faz esbarrar com o intolerável do sem-sentido.

Lacan, a respeito do sujeito e de sua relaçấo com o desejo, salienta que "[...] a única coisa da qual o sujeito pode ser culpado é de ter cedido do próprio desejo" (Lacan, 1988 [1960], p. 385), que aqui não se confunde com o simples querer. $\mathrm{O}$ que se coloca aqui diz respeito náo a um maior ou menor conhecimento do objeto de desejo, mas a um "[...] compromisso - ou descompromisso - com a condição desejante" (Kehl, 2009, p. 58). Lacan usa o termo "culpa moral", ou ainda, "covardia moral" para conceituar essa demissão subjetiva diante de sua condição desejante. $\mathrm{O}$ covarde seria aquele que faz de sua palavra uma mera repetição do discurso do Mestre, numa palavra esvaziada de qualquer relação com o saber inconsciente (Kehl, 2009, p. 194). Dessa palavra vazia sabemos que o que ela faz é obscurecer a posição inconsciente do sujeito e, concomitantemente, a posição deste em relação a seu desejo.

Aqui se faz necessário um pequeno parênteses, a título de esclarecimento sobre algumas leituras muito difundidas da psicanálise. 
Leituras muitas vezes feitas superficialmente e que terminam por associar à psicanálise a determinados jargóes que em nada ajudam tanto àqueles que buscam em seu arcabouço teórico um ponto de reflexão para seus estudos, quanto àqueles que nele se apoiam para refutar ou olhar criticamente seu discurso.

O primeiro esclarecimento é referente ao conceito de Inconsciente. Conforme salienta, de maneira pertinente, Luis Alfredo Garcia-Roza:

O inconsciente freudiano não é uma substância espiritual, contrafação da res cogitans cartesiana, não é um lugar ou uma coisa. [...] Dizer que uma representação é inconsciente não significa outra coisa senão que ela está submetida a uma sintaxe diferente daquela que caracteriza a consciência. [...] Assim, a cisão produzida na subjetividade pela psicanálise não deve ser entendida como a divisão de uma coisa em dois pedaços, mas como uma cisão de regimes, de formas, de leis. "Obedecer a dois senhores", como nos diz Freud, é obedecer a leis diferentes, assim como as formaçôes de compromissos são compromissos entre exigências legais diferentes (1997, p. 174).

Dessa forma, tal como salienta Freud em seu artigo O Inconsciente, é nas lacunas das manifestaçóes conscientes que devemos procurar o caminho do Inconsciente. Dentro dessa perspectiva, o Inconsciente não tem a ver com o profundo, com uma essência escondida nos recônditos do ser, como muitos preferem equivocadamente tomá-lo. Trata-se daquilo que está mais à vista, como esclarece Lacan em $O$ seminário sobre a Carta Roubada (1957), mas que, ainda assim, não vemos.

Outra leitura comum de se fazer é a de que o saber psicanalítico, ao conceituar e defender o inconsciente como um saber que não se sabe, estaria abrindo espaço para que o sujeito se exima da responsabilidade de seus atos. E aqui entra toda uma discussáo a respeito da ética em psicanálise, que não cabe abordar aqui. Afinal, eu não tenho culpa, foi inconsciente. Entretanto, é importante salientar que o Inconsciente na psicanálise não é adjetivado, ou seja, não é uma qualidade, a de estar inconsciente como uma oposiçáo a estar consciente. Ao substantivar o Inconsciente, Freud o insere na dinâmica estrutural do aparelho psíquico. Nesse caso, ele é determinante dessa estrutura. Poderíamos dizer que o inconsciente é incognoscível, mas é possível operar com ele, a partir de seus efeitos. Pensar o Inconsciente como estruturante do aparelho psíquico implica dizer que o desco- 
nhecido, esse saber que não se sabe, tem maior poder de operação nessa estrutura. Nessa ótica, poderíamos dizer que o Inconsciente tem sua vertente de ato, na medida em que o sujeito é agido por ele.

Se o inconsciente náo está escondido, mas opera a olhos vistos, se não há qualquer necessidade de ir até os recônditos mais profundos do ser para descobrir o que se esconde, iluminando o que está escuro fora dos domínios da consciência, o que está em jogo aqui é a escuta desses efeitos, a escuta para Isso que age. Isso implica que, a todo sujeito, é dada a tarefa de se haver com a questáo de seu desejo. Desse modo, a psicanálise vem afirmar, em última instância, que somos responsáveis por nosso Inconsciente. Ou seja, permanecer ignorantes quanto ao próprio Inconsciente, e em larga escala sobre os seus efeitos, é um ato de escolha e somos responsáveis por essa escolha. E essa responsabilidade aqui não tem a ver com culpa, mas com uma implicação do sujeito em relação a seu próprio desejo e discurso.

\section{Inconsciente e Corporeidade}

Problematizar essas questóes se faz necessário (e me parece que elas não são estranhas à construção grotowskiana), pois é essencial o exercício de uma escuta dessas instâncias para que possamos perceber, nessas malhas discursivas, seu momento dogmático e o momento no qual re-produzimos o discurso, o repetimos à revelia do nosso desejo e acabamos por trair nossa via.

Buscarei aqui tecer um paralelo entre essa questão apontada pela psicanálise e a via negativa como base para o trabalho com o corpo, interrogando-me sobre escolhas, sobre o que faz moldura para o nosso olhar quando vamos trabalhar nosso corpo e o corpo do outro. Trata-se, no tocante ao trabalho corporal, de evitar a ignorância relativa aos efeitos do Inconsciente no corpo.

Podemos pensar que esse plano de visibilidade emoldura, delimita e faz visível um horizonte de experiências, assim como uma maneira de ouvir o corpo - o do outro e o nosso. Entretanto, é sabido que, nesse processo de dar forma, imprimimos não só os contornos, mas também aquilo que, suprimido, recalcado e/ou silenciado, acaba por ser suprimido desse. $\mathrm{O}$ que nos faz pressupor que a conceituação de corpo é fruto de uma construção que opera tangenciando os vazios e os recalques de cada prática e dos sujeitos nela envolvidos.

De forma que cabe perguntar: Que corpo ou ideia de corpo é essa de que nos ocupamos em nossos trabalhos? O que está em jogo 
nessas diferentes malhas de apreensão do corpo? Enfim, como artistas de teatro e de dança, com que corpo lidamos?

Estes questionamentos não são novos para aqueles que trabalham com o corpo. Entretanto, acredito na importância de colocar essas perguntas também em sua negativa: De que corpo não se fala? De que corpo ou incidências corporais se foge? De qual corpo não se quer saber?

Trabalhar com essa questão pela via negativa me parece, tendo em vista meu objeto, uma opção mais interessante. Tal proposta não é descabida, principalmente se levarmos em conta que o corpo, assim como os diferentes discursos instituídos sobre ele, traz em seu rastro uma problemática: o que fazer com aquilo que do corpo excede, institui um fora, ultrapassa nossa capacidade de entendimento e de organização?

Se concordarmos que o trabalho artístico deve ser assumido no desejo, uma via se desenha e um vazio se revela, restando ao artista assumir sua condiçáo desejante diante daquilo que se apresenta ora como escolha, ora como urgência muda. Desejo que, pouco a pouco, torna-se também uma posição a ser assumida frente a determinado contexto de pensamento sobre o corpo, que acaba por refletir em nossas práticas nos universos da dança e do teatro. Contexto que muitas vezes se sustenta, a exemplo de nossa contemporaneidade, no discurso da diversidade e em uma enorme negação da diferença. O que nos leva a uma planificaçáo de nossos desejos, acostumados a responder à demanda do Outro.

Este texto pretende tangenciar a via negativa no trabalho do ator, perguntando sobre esse plano de visibilidade dado pelo Outro, perguntando-se sobre esse si que se vê muitas vezes autorreferenciado pelo recorte do Outro no trabalho do ator.

Sabemos que esse plano de visibilidade - que atravessa as coisas e as ilumina segundo um regime próprio -, se vê dependente do ponto a partir do qual olhamos e recortamos a realidade, construindo-a para nós. Entretanto, cabe frisar, com a ajuda da psicanálise, que esse ponto é dado pelo Outro que totaliza o que, na verdade, é residual e fragmentário na experiência do sujeito, inclusive a experiência de um si e de construçáo de um corpo e de uma identidade.

Em última instância, podemos afirmar que essa realidade que nos faz construir um corpo e uma identidade é de origem fantasmática e nela incide o recorte do Outro. 
Tal como salienta essa importante citaçáo de Lacan:

O homem está capturado pela imagem de seu corpo. Este ponto explica muitas coisas e, em primeiro lugar, o privilégio que tem a dita imagem para ele. Seu mundo, se é que esta palavra tem algum sentido, seu Umwelt, o que o rodeia, ele o corpo-reifica, o faz coisa á imagem de seu corpo. Não tem a menor ideia, certamente, do que acontece neste corpo (Lacan, 1985 [1975], p. 3, grifo do autor).

Lacan, em seu texto $O$ estádio do espelho como formador da função do eu, demonstra o mecanismo que utilizamos para imaginar que possuímos algo como uma identidade coerente. Vemos que o espaço virtual por trás do espelho plano é onde o sujeito imagina que o seu "eu" existe como unidade. Esse espaço virtual contém também o olho do sujeito, mostrando que na relaçáo do Imaginário com o Real tudo depende da situaçấo do sujeito, seu lugar no mundo simbólico, ou seja, depende daquilo que faz recorte para o seu olhar ${ }^{4}$.

Para Joel Birman (2007), Lacan retoma de maneira brilhante a questão do narcisismo na obra freudiana quando este (Freud) define o eu como um eu corporal ao desenvolver o conceito de captura para esboçar as relaçóes entre eu, o corpo e a imagem.

Entretanto, tal como sinaliza Lacan, esta transposição nunca será integral, posto que teremos como resultante, dessa operação, um resto náo-especularizável. Existe algo do corpo que permanece como resto e, portanto, inacessível à apreensáo por parte do sujeito via imagem.

Sabemos que o $e u$ desconhece a função de sua imagem como alienação ao Outro, de modo que podemos afirmar que o eu é o lugar do desconhecimento d'Isso que o atravessa. Pensado por esse viés, o corpo se constitui como uma realidade instável. Mantém-se uma relação tumultuada entre o invisível que nos constitui e o plano de visibilidade que nos permite reconhecermo-nos como um corpo.

É exatamente essa articulação/problematização do sujeito e seu desejo diante da delimitação da linguagem que parece estar em jogo no percurso de Grotowski. O artista em todo seu percurso desfecha críticas incisivas exatamente aos diferentes modelos que criamos, propostos para "dar conta" de nosso horizonte de experiências, com o intuito de silenciar aquilo que, excluído, silenciado ou recalcado, pede vida, quando náo constitui a própria vida no que ela tem de irrepresentável - a ponta da lança da alteridade de nosso desejo, de nosso sopro vital, de nossa carne que se enovela ao vazio, ao resíduo, ao náo-saber de si. 
$\mathrm{Na}$ radicalidade de algumas propostas - como é o caso do desejo de Grotowski - a dimensão do fazer artístico se enovela de tal forma com o sujeito que é o próprio si do famoso trabalho sobre si que se vê desarticulado, lançado a questionamentos. De que si estamos tratando?

De Grotowski a sensação que perpassa é a de um trabalho que se sustenta, tanto na prática quanto na sistematização desta em palavras, tendo como base de sua tessitura um certo trabalho sobre o negativo.

Como se, na relaçáo com aquilo que se institui como saber, tivéssemos que refazer continuamente o trabalho artesanal de tatear, bordejar aquilo que, na experiência, se mostrou como horizonte - um horizonte que náo extingue de seu panorama o contato com o desconhecido, com o vazio e com as hiâncias do próprio desejo e fazer do artista. Encontrar uma forma de fazer essa passagem - entre a experiência e a palavra, entre saber e não-saber em busca do sujeito - é uma preocupação que podemos ver nos textos de Grotowski. A questáo da transmissão do saber se ancora, aí, na dialética paradoxal entre o inexprimível e o exprimível, entre Real e Simbólico. Segundo Flaszen, tal dialética está presente em todo o percurso de Grotowski. Encontrar a palavra certa, assim como um jeito certo de fazer, torna-se uma tarefa difícil, até mesmo impossível, tendo em vista que toda metodologia se sustenta pelo que dali se ausenta sob a forma de um sintoma.

Defendo que é algo desse desconhecido, referente a uma certa relaçáo com o saber, que se transmite através do fazer grotowskiano. Dessa forma, podemos pensar que, mais do que os conteúdos representados por diferentes exercícios que acabam por constituir os diferentes treinamentos e metodologias, o que prioritariamente se transmite é algo dessa relaçáo do artista com o saber, o que se configura claramente em sua proposição de uma via negativa, ou seja, de uma metodologia que se sustenta exatamente na negaçáo desta, como um antimétodo.

Segundo Lima (2012) havia em Grotowski um mal-estar frente à leitura, aplicação e apropriação de ideias e exercícios apresentados em seus textos. Esse mal-estar se apresenta pelo questionamento por parte do artista da ideia corrente de treinamento como base para se adquirir certo controle sobre o corpo. O problema residiria em dois pontos: primeiro na apropriação de modelos sem se questionar sobre o que os sustenta, mantendo-os numa espécie de pedestal e acreditando 
que ali, no Outro, reside a resposta sobre seu fazer; segundo referente à ideia de que é pela via de um corpo bem preparado que o ator seria capaz de se colocar em contato com o corpo-vida ou conduzi-lo ao que Grotowski passou a chamar ato total. Diz Grotowski:

Frequentemente [...], me ocorre encontrar grupos que começam pelos exercícios tomados emprestados do meu livro. [...] Crê-se que um certo tipo de training preparatório, submete-se a ele por um período de tempo convenientemente longo, seja capaz de conduzir o homem ao ato. Mas o que recebe aquele que se exercita durante essa espera é apenas uma peculiar ilusão (apud Lima, 2012, p. 260).

Para o artista não adiantava buscar essas chaves miraculosas, na esperança de que elas nos dispensariam de termos que nos haver com nós mesmos (Lima, p. 222). Esse é o momento em que, sedados pelo gozo de pertencer a um modelo, de podermos nos encaixar, significar e ganhar uma consistência de ser, negamos o ponto de angústia que nos liga a nosso corpo e desejo, posto que esse ponto remete a uma queda, uma renúncia, uma perda. Uma perda de corpo que acarreta com ela uma renúncia ao gozo que obtemos quando nos alienarmos e nos enovelarmos nessas diferentes malhas discursivas e imaginárias.

De modo que poderíamos nos perguntar se a insistência em manter o Outro consistente náo serve para mantermos a nossa consistência - de eu e de corpo - mesmo que imaginária. O artista já denuncia nesse processo que essa situaçáo de alienação é mantida para que o sujeito-ator náo tenha que lidar com a singularidade de sua experiência, que envolve prioritariamente o não-saber.

Tatiana Motta Lima afirma que o artista se posicionará contrariamente à formação concedida aos atores, denunciando o foco desta em "[...] ensinar o ator a observar, controlar e manipular os seus chamados instrumentos vocal e corporal - dissociando o ator de seu corpo/voz - com vistas à produção da expressão requerida" (Lima, 2012, p. 254). Tais processos acabam náo levando em conta os processos singulares de cada ator, seus fluxos, associaçóes, temporalidades.

O que se nega nessa postura objetivante do corpo é exatamente seu ponto de queda, aquilo que escapa a essa imagem dada pelo Outro: seus movimentos afetivos, assim como os trilhamentos pulsionais e impulsos particulares que o habitam.

Grotowski criticava, portanto, esse tipo de profissionalismo alienado e seu interesse voraz por técnicas e exercícios, tendo em vista 
que dentro desse horizonte tudo tende a se transformar em truques. Para o artista "[...] o ato precisava ser humano e não profissional" (Grotowski apud Lima, 2012, p. 255).

Outra crítica feita por Grotowski diz respeito à ideia de aperfeiçoamento. Essa ideia despreza o aqui e agora da experiência, sem o qual nenhum ato seria possível. Isso se deve ao fato de que a ideia de aperfeiçoamento pertence a um tempo cronológico e linear, negando nesse o presente, e que teria como resultante mascarar uma operaçáo de recalque que se configuraria como o desejo de evitar o ato (Lima, 2012). Come se, enquanto sigo cronologicamente me aperfeiçoando, eu impedisse a irrupção de um corpo outro, estranho; desse invisível que age e no qual o eu náo se reconhece. De forma que cabe nos perguntarmos sobre esse processo incessante pelo qual nos asseguramos do corpo sem ter que nos haver com o que do corpo náo se segura, posto que escapa das malhas do simbólico e da construção imaginária.

Arrisco a dizer que o que se nega nessa temporalidade cronológica é a escansão própria da temporalidade do sujeito do inconsciente, seu caráter pulsativo, evanescente, de abertura e fechamento. Lacan ao referir-se, em seu Seminário 11, à primeira característica do inconsciente afirma que este se manifesta para nós como algo que fica "[...] na espera (dans l'attente), na região (dans l'airé), eu diria, do não nascido" (Lacan 1998 [1964a], p. 29).

Nem irreal nem não real, nem ser nem não ser, esse náo nascido, completa Lacan, é da ordem do "não-realizado". Desse modo, devemos aqui nos ater à fulguraçáo instantânea em que ele se nos apresenta, como algo que nos visita ao mesmo tempo em que se retira. Esse tempo é singular e depende de um estar em trabalho que não tem necessariamente a ver com a ideia de desenvolvimento ou aperfeiçoamento dentro de uma cronologia ascendente. Esse tempo opera por saltos, nele algo se deixa pegar para, logo em seguida, nos jogar no mais absoluto marasmo, de modo que os momentos de tédio em que nada aparentemente acontece, assim como a angústia que em geral deles advém, podem fazer parte do estar em trabalho, na medida em que algo se passa e nos coloca em ponto de padecer d'Isso que age à revelia da minha vontade.

\section{A Via Negativa e o Teatro}

Se concordarmos com Tatiana Motta Lima que "[...] o trabalho sobre si em Grotowski é uma espécie de seta na direção daquilo que é 
desconhecido (marginal ou desejante) em cada um" (2011, p. 4), sendo prioritariamente um trabalho que se faz pela via negativa buscando o afastamento das "[...] subjetividades bloqueantes, anestesiadas, fechadas sobre si, inerciais, que buscam a todo custo o controle, a segurança, a estabilidade" (2011, p. 4) podemos pensar que, em certa medida, o que se configura na construção grotowskiana é pensar o corpo e o ofício do ator como espaço de passagem para a descoberta/ criaçáo de um novo corpo que se opera a partir de uma travessia em que o próprio si do trabalho sobre si é colocado em questão.

Flazsen, em seu texto Depois da vanguarda, delineia o campo de pesquisa do teatro laboratório defendendo que esse é "[...] uma disciplina que possui princípios próprios, uma matéria-prima específica, conteúdos e fins próprios tais que nenhum outro campo da atividade humana pode substituí-lo" (Flaszen, 2007 [1967], p. 113).

Para o autor, a matéria-prima do teatro é a vida, mas não qualquer vida, não a que se torna hábito, mas aquela que escapa à tessitura deste. Faz-se necessário, nesse cotidiano de coisas já habitadas, encontrar o inabitado. Aquilo que o hábito vela torna-se necessário desvelar.

O que rege o percurso de Flaszen nesse texto é a tentativa de precisar o que restaria ao teatro da modernidade, tendo como ponto de partida, para a construção de sua análise, as mudanças operadas no teatro pelo movimento vanguardista. Ele salienta que, se por um lado haviam levado a decomposição da língua ao seu limite extremo (sendo Beckett aquele que levou isso a consequências extremas, ao problematizar a relação da linguagem com o silêncio e o esvaziamento do sujeito como aquele capaz de se dizer ou se reconhecer no tecido da língua), por outro lado, os atores não caminharam frente a esse novo teatro. As vanguardas não se ocuparam da arte do ator. $\mathrm{O}$ ator, na visão de Flaszen, permaneceu apegado aos seus velhos clichês e a uma atuação fria e mecânica.

Desse modo, o autor defende a necessidade do teatro se voltar para a partitura dos impulsos e das reações humanas. Diz: "O processo manifestado através das reaçóes corpóreas do organismo vivo. Eis a essência da teatralidade" (Flaszen, 2007 [1967], p. 116).

Para esse processo, sabemos que Grotowski elege a via negativa para o trabalho do ator, via esta que busca não o acúmulo de habilidades, mas a eliminação dos bloqueios que impedem a livre circulação dos impulsos vitais no corpo do ator. Entretanto, Grotowski 
nos atenta para o fato de que esse processo de desnudamento náo é voluntário, no sentido que náo se espera um controle do ator em relação a esse processo. Para o artista: "O estado mental necessário é uma disponibilidade passiva para realizar um papel ativo, um estado no qual não se quer fazê-lo, mas antes renuncia-se a não fazê-lo" (Grotowski, 2007 [1965b] p. 106).

$\mathrm{O}$ ator se tornaria, assim, um canal para a descoberta de seus impulsos mais primários, de um invisível que move, que atua. De forma que, diante daquilo que se silencia em nós e do qual não queremos nada saber resta renunciar ao fazer, ao saber fazer com seu corpo. $\mathrm{O}$ corpo torna-se assim espaço de uma escuta ativa, escuta que busca através do despojamento das defesas, um estado de disponibilidade no qual se torna possível lidar com o recalque e com aquilo que no corpo se silencia.

O nosso método não é um método dedutivo para colecionar técnicas. Aqui tudo se concentra na "maturação" do ator que é expressa por uma tensão em direção ao extremo, por um completo desnudar-se, por um revelar a própria intimidade [...]. O ator faz total doaçáo de si mesmo. Essa é uma técnica do transe e da integraçấo de todos os poderes psíquicos e físicos do ator que emergem dos estratos mais íntimos do seu ser e do seu instinto, irrompendo numa espécie de transiluminação (Grotowski, 2007 [1965b], p. 106).

O que considero importante de se levar em conta é como a via negativa acaba por alargar e pôr em xeque, seja em busca da especificidade da arte teatral, seja pela busca da intimidade do ator, a própria ideia de corpo no universo teatral. $\mathrm{Na}$ visão grotowskiana, é no embate com seu corpo, com seus impulsos e silêncios que o ator constrói. Em Grotowski essa realidade corporal nos traz um conhecimento concreto, mas que, no entanto, "[...] náo pode ser idêntico ao conhecimento do cientista" (Grotowski, 2007 [1972], p. 202), posto que age "na interpenetraçáo de consciente e inconsciente" (Grotowski, 2007 [1972], p. 202). Assim, o espaço do corpo torna-se espaço de contato entre aquilo que já se encontra fixado numa memória e aquilo que invade como um "além da memória" (Grotowski, 2007 [1969], p. 173). Somos convidados ao desconhecido, numa atitude de desvelamento, em busca do que é mais íntimo. Desvelamento que não deixa de ser visto, nesse sentido, como uma aproximação íntima demais. 
Portanto, é na dimensão do exterior e, sobretudo do desvanecimento do sujeito, que essa poética negativa se sustenta. No processo de busca de revelação da intimidade, acaba-se por demarcar um ponto exterior a essa, um ponto de perda em que ambos, o teatro e o corpo do ator, se veem tragados para uma dimensão de borda, tangencia a vida e com ela o Real.

Voltemos à relação do artista com o saber. Vimos que a identificação comporta um risco: o da identificação cega com as palavras e com o fazer do outro, a ponto de não sabermos mais separar o que é o nosso caminhar daquilo que o outro construiu, de não sabermos nos desembaraçar do desejo do Outro. Dentro dessa perspectiva mitificamos o outro e seguimos desenhando sobre o pontilhado, seguindo métodos, institucionalizando saberes. Tornamo-nos repetidores de fórmulas prontas, incapazes de dar o salto que nos separaria do Outro, inaugurando um fazer. É que o separar do Outro nos joga no vazio do traço, exige trabalho, criação. Dessa forma, diz Grotowski, nesse processo de herdar se faz necessário seguir sua própria natureza, se colocar questôes.

Diz Grotowski:

Certas perguntas não têm sentido: "Stanislavski é importante para o novo teatro?" Náo sei. Há coisas novas como as revistas de moda. E há coisas novas, mas antigas, como as origens da vida. Porque perguntam se Stanislavski é importante para o novo teatro? Dê tua resposta a Stanislavski - que náo se baseie na ignorância da coisa, mas em seu conhecimento prático. Ou és criativo ou não. Se és, de algum modo o superas, se não és, és fiel, porém estéril (1993, p. 18).

Assim, o herdar não pode ser pensado como destituído de um fazer, de uma passagem do sujeito onde algo do seu traço singular na relaçáo com o Outro se revela.

O que podemos acompanhar dessa relação com o saber, tomando como base o texto Resposta a Stanislavski é todo um trabalho do artista para apontar seu processo de construção ímpar a partir da herança deixada pelo encenador russo. $\mathrm{O}$ artista aponta nesse percurso como, pouco a pouco, a palavra método foi ganhando significados distintos em seu fazer:

Existe o desafio ao qual cada um deveria dar uma resposta própria. Cada um deveria ser fiel à própria vida. [...] Em todo caso, a experiência da vida é a pergunta, enquanto que a criação na verdade é simplesmente a resposta. Entáo o 
método - no sentido de um sistema - não existe. Não pode existir de outra maneira que como desafio ou chamado. E não se pode jamais prever qual será a resposta de algum outro. E muito importante estar preparado para o fato que a resposta do outro será diferente da nossa. Se a resposta é a mesma, então é quase seguro que é falsa (Grotowski, 1993, p. 19).

Arrisco a dizer que o desafio que aqui se delineia é o do sujeito diante da vida ou, se preferirmos, diante do inominável de seu desejo e das forças pulsionais que o habitam. "Como tocar o que náo é tangível?”, pergunta Grotowski. No que ele salienta que é encontrando "[...] vias concretas até o que é secreto, misterioso" (Grotowski, 1993, p. 20).

Tratava-se então de buscar não os meios, as habilidades para fazê-lo, mas as vias concretas de ação. Grotowski salienta que esse retorno de Stanislavski sobre as açóes físicas o levou a descobertas consideradas por ele como uma espécie de revelação:

[...] que os sentimentos não dependem de nossa vontade. $\mathrm{Na}$ fase precedente isto ainda não era claro para ele. Buscava a famosa "memória emotiva". Seguia acreditando que o recurso da recordação de diferentes sentimentos significava a possibilidade de voltar aos sentimentos mesmos. Nisto havia um erro - a fé no fato de que os sentimentos dependem de nossa vontade (Grotowski, 1993, p. 20).

$\mathrm{Na}$ impossibilidade de resgatar os sentimentos a partir da memória se faz necessário o retorno ao corpo. O que fica evidente é que o que aqui se delineia é um trabalho sobre as açóes, sobre os seus detalhes. É como se, no rigor da escuta desses detalhes, uma tessitura interna encontrasse caminho no corpo - tessitura que, como vimos, tem relação com um mapeamento de uma cartografia afetiva presente no corpo.

Porque frequentemente nos parece que fazemos algo, enquanto na realidade estamos fazendo outra coisa. A análise precisa desse tipo de açóes teve início com Freud, porém, já no Idiota de Dostoievski temos, por exemplo, a história de um homem que olha na vitrine uma faca. Fazia algo completamente diferente do que lhe parecia fazer. Inconscientemente sua natureza se preparava para algo diferente daquilo que sua consciência estava analisando. Assim posto, ter consciência do que se faz não é tudo, porque não envolve a integridade. [...] Stanislavski compreendia que este dilema existe e buscava - a seu modo - como tocar indiretamente o que é inconsciente (Grotowski, 1993, p 22). 
Podemos depreender que aqui a ação é tomada como uma espécie de isca para que algo, enovelado pela própria ação, se revele. Entretanto, há uma relação que aqui se insinua que merece ser pensada e problematizada: aquela que acaba por enlaçar a memória ao corpo.

Mais do que uma ação executada pelo corpo, o que parece ser acentuado na ideia de ação física é o fato de elas se darem em ligação/ relação com o outro, com o entorno. De modo que concordamos com Lima quando essa nos adverte que, nesse ponto da construçáo grotowskiana, não se trata de pensar que esta ação se dá num movimento de introspecção, mas a partir da vertente, ou melhor, da noção de contato. Importante ficar atento à citação de Lima de como essa via de contato parece um caminho para ampliar a dinâmica da açáo para além do recorte efetuado pelo narcisismo:

Para Grotowski, o ator não deveria ficar concentrado "no elemento pessoal como um tipo de tesouro" [...], "procurando a riqueza de suas emoçôes". Esse seria "um ator que apenas estimularia artificialmente o processo interno, um ator imerso em uma espécie de narcisismo", [...]. Estar em contato significava, concomitantemente, perceber o 'outro' e reagir intimamente de acordo com essa percepçáo. Grotowski contrapunha o contato, que forçaria o ator a modificar o seu jeito de agir, ao padrão que "está sempre fixo". Também importante na ideia de contato é que a reação não era nem premeditada, nem resolvida a posteriori: o contato pressupunha uma escuta que era imediatamente reação (2012, p. 163).

Assim, podemos pensar a ação física não como um simples fazer, mas como um fazer em passagem, no hiato que se abre entre aquilo que realizo e o que julgo realizar, entre eu e Outro. Sob esse ângulo existe algo do corpo que se dirige para o entorno e algo que retorna para o próprio corpo provocando reações, relaçóes, derivações. Cabe a pergunta: ativa-se aí uma memória?

Aqui o campo da ação se abre para o invisível que age, para os intervalos, para uma erótica, para um campo de significância.

Tomemos Grotowski e sua reflexão acerca da memória:

Pensa-se que a memória seja algo de independente do resto do corpo. Na verdade, ao menos para os atores, é um pouco diferente. $\mathrm{O}$ corpo não tem memória, ele é memória. $\mathrm{O}$ que devem fazer é desbloquear o corpo-memória. Se começam a usar detalhes precisos nos exercícios "plásticos" e dão o comando a vocês: agora devo mudar o ritmo, agora devo mudar a sequência dos detalhes, etc., não liberarâo o corpo memória. Justamente porque é um comando. Portanto, é a 
mente que age. Mas se vocês mantêm os detalhes precisos e deixam que o corpo determine os diferentes ritmos, [...] quase como pegando os detalhes no ar, então quem dá os comandos? Não é a mente nem acontece por acaso. Não sabemos nem mesmo como acontece, mas é o corpo-memória, ou mesmo o corpo-vida, porque vai além da memória. O corpo-vida ou o corpo-memória determina o que fazer em relação a certas experiências ou ciclos de experiências de nossas vidas. Então qual é a possibilidade? É um pequeno passo rumo à encarnação da vida no impulso (Grotowski, 2007 [1971], p. 173).

\section{O Trabalho sobre o Negativo}

Se concordarmos com Roland Barthes de que a escritura, como operação poética, tangencia o impossível, pensado como aquilo que não se deixa capturar pelo pensamento, que náo pode ser atingido, que escapa ao discurso, mas que se anuncia sob outra medida que (não) a do poder, devemos pensar que a poética da corporeidade também buscará tangenciar esse ponto impossível, ponto cego, ponto de impoder que, invisível, não especularizável, é o que sustenta nossas referências corporais, ponto de silêncio no qual um rumor se dá e nos visita, impronunciável. Ponto que acaba por demarcar um exterior, um fora.

Entretanto, é importante reforçar que esse fora, longe de instalar uma totalidade com aquilo que se encontra dentro - o que nos levaria a tomar a poética da corporeidade como o encontro com um ponto de não cisão -, marca exatamente o corte, a descontinuidade. E é devido a esta descontinuidade que algo da ordem do não-especularizável tem alguma chance de advir. É exatamente porque há um descentramento do sujeito, que esse confusionamento entre eu/outro, o que vemos/o que nos olha se revela. No campo das artes cênicas, defendemos que é também em função deste descentramento - marca da fenda, do traço, da ruptura - que podemos nos perguntar sobre o que nos chama (isso que age) enquanto estávamos fazendo ou pensávamos fazer alguma coisa, enquanto agíamos.

Acredito que isso se reflete na ou é decorrente da forma como pensamos a vertente do saber tornando-a equivalente ao conhecimento. Ao problematizar essa questáo, Lacan evoca o cogito inicial, tal como postula Descartes, afirmando que neste "[...] o que visa o eu penso no que ele bascula para o eu sou, é um real" (Lacan, 1998 [1964b], p. 39). Entretanto, Lacan sinaliza que nessa afirmação, 
[...] o verdadeiro fica de tal modo de fora que é preciso que Descartes se assegure de quê - senão de um Outro que não seja enganador e que, por cima de tudo, possa garantir, só por sua existência, as bases da verdade, possa lhe garantir que há em sua própria razão objetiva os fundamentos necessários para que o real mesmo de que ele vem se assegurar possa encontrar a dimensão da verdade (1998 [1964b], p. 39).

Se, para me garantir como sujeito de certeza, é preciso sustentar um Outro com peso de verdade, para que ele me assegure de que o que vejo é objetivamente o que se coloca sob meus olhos, poderíamos pensar que sustentamos esse Outro no lugar da verdade para sustentarmos a nós mesmos como sujeitos de certeza e de conhecimento.

É exatamente a dimensão de conhecimento vinculada ao saber, juntamente com aquilo que é passível de ser objetivado, que merece ser questionada. Para Lacan essa configuraçáo se sustenta na geometria, tomada como modelo para se pensar a consciência reflexiva. Geometria pensada sob a égide da perspectiva, que faz com que cada ponto num lugar corresponda ao outro. Donde podemos deduzir que é a partir desse lugar - de seu olho-ponto geometral - que o sujeito olha, se reconhece e se representa, alijado do quadro. Entretanto, Lacan nos adverte que o lugar do sujeito é diferente do lugar do ponto geometral que define a ótica geométrica, posto que o sujeito em causa não é o da consciência reflexiva, mas o do desejo.

Nesse ponto algo se pinta e que de modo algum, salienta Lacan, é simplesmente uma relação construída tomando algo como objeto, mas sim uma impressão, "[...] borboteamento de uma superfície que não é, de antemão, situada para mim em sua distância. Aí está algo que faz intervir o que é elidido na relação geometral - a profundidade do campo, com tudo que ela apresenta de ambíguo, de variável, de não dominado de modo algum por mim" (Lacan, 1998 [1964c], p. 95).

Desse modo podemos depreender, diante do exposto, que o sujeito do conhecimento tem que se representar sob o peso de se colocar fora do quadro e, portanto, apartado d'Isso que age. Para Lacan é a própria dimensáo do saber que se encontra alijada dessa experiência. O que faz com que ele afirme que "[...] o sujeito do inconsciente se manifesta, que isso pensa antes de entrar na certeza" (Lacan, 1998 [1964b], p. 40). Pensemos entáo n'Isso que age à revelia de nosso conhecimento. Trata-se aqui de tomar saber e conhecimento como universos distintos, tendo em vista que, ao admitirmos um Isso que 
age e que pensa apartado da esfera do conhecimento, postulamos não só uma diferenciação entre esses dois campos, como também questionamos o próprio lugar de certeza do sujeito da experiência.

O saber, dentro dessa perspectiva, se difere do conhecimento tendo em vista que ele não é um conteúdo ideativo, algo que pode permanecer como uma representação exterior à experiência. Na dimensão psicanalítica o saber não é algo de que se possa vir a ter um conhecimento assimilável pelo sujeito. Trata-se de uma apropriação de algo que se faz na experiência, sendo que essa apropriação não quer dizer que o sujeito entenda ou signifique sua experiência. O saber da experiência não garante que o sujeito conheça o que sua experiência representa.

Segundo Ana Costa, a experiência assim pensada não pode ser reduzida à esfera do conhecimento, à referência a um símbolo abstrato, ela precisa passar pelo corpo, se faz na sua relaçáo com o outro e com o real. É somente essa natureza mais extensa da experiência que produz um registro que a teoria lacaniana denominou de saber. Como se pode depreender, o saber aqui se diferencia da informaçáo e do conhecimento, na medida em que ele é necessariamente corporal e, por isso, também inconsciente (Costa, 2001, p. 33).

Desse modo, a esfera do saber, para Lacan, é conjunta a do registro, de algo que permanece impresso a partir de uma experiência, corporal e inconsciente, como traço obliterado, apagado e que, no entanto, permanece, insiste, gerando efeitos, afetos, deslizamentos.

Como não pensar então nos diferentes atos falhos do corpo, ou nos seus sintomas que, ignorados como não tendo nada a dizer a respeito do corpo ou da corporeidade do sujeito, são relegados ao silêncio. Perguntemo-nos se não estamos substituindo a singularidade da diferença - representada aqui pela singularidade da escolha dos destinos pulsionais e da geografia afetiva de cada sujeito - pela repetição do idêntico - representada pelos diferentes modelos que acabam veiculando um discurso único sobre o corpo. Perguntemonos também se não insistimos em manter esse lugar de verdade sobre o corpo para evitarmos exatamente ter que se haver com o corpo no momento em que esse, na singularidade de seus desenhos pulsionais, nos faz enigma, para não termos que nos haver com a dimensão de ignorância, de não-saber, que concerne nossa relação com nosso corpo.

O questionamento incide, portanto, na forma como sustentamos nossa escuta no que tange o trabalho corporal. Tatiana Motta Lima 
(2012, p. 4) problematiza, por exemplo, nosso uso de um "escuta objetivante" que mantém um espaço exterior a ser lido, rápido e prontamente pelo ator e ao qual se deve estar atento e sintonizado. A pesquisadora questiona e percebe certas vezes uma "atenção hiperativa que tudo quer abarcar" e com ela a presença de "um corpo-imã que busca trazer o todo e o tudo para si" ou entáo "levar o si para o tudo e o todo" (Lima, 2012, p. 5). O que seria essa ansiedade, esse trazer tudo para si, senão o ignorar, na dimensão da experiência, o saber do corpo; tomado aqui como esse ponto que resiste à dissecação, à nossa planificaçáo consciente, à nossa necessidade de abarcar, de desvendar, de sistematizar, de trazer tudo para si, a partir de nosso crivo, de nosso eu, de nossa leitura. O que se evita aqui, o que não é suportado é a angústia do encontro com o Real do corpo, sua opacidade, seu ponto de perda, a partir do momento que sustentar esse encontro representa a perda desse si estável, capaz de ler, catalogar, dar sentido rapidamente, prontamente.

Dentro desse ponto de vista podemos dizer que estamos no trabalho, mas náo estamos em trabalho, posto que, no primeiro, movimentamo-nos bastante, fazemos coisas, nos informamos e enformamos, mas nada se movimenta em nós. Estar em trabalho não é trabalhar o corpo, fazer coisas com este, mas mapear os efeitos de seu desdobramento quando nos pomos a ouvir. É nesse espaço de limiar que se deve pensar a escuta. Náo se trata, portanto, de acumular saberes, mas de uma certa intimidade com esse espaço de limiar, em que nos avizinhamos do informe, do estrangeiro, do exterior, do estranho...

De modo que cabe questionar até a ideia de presença quando essa se confunde com prontidáo, assim como a ideia de ação quando essa se confunde com reaçáo. Estar no aqui e agora acaba se tornando responder/reagir rapidamente - ação/reação, estímulo/resposta. Concordamos com Lima quando ela diz que muitas vezes o que o ator acessa é uma resposta automática e padrão. Poderíamos nos perguntar, parafraseando Alfredo Jerusalinsky (2012, p. 9), se náo estaríamos adaptando nossa experiência do corpo como espaço de investigaçáo de um saber para o que poderia ser chamado de Actor automaticus.

"Algo aconteceu, é preciso reagir, é necessário estar no momento presente!" Somos tomados por uma série de demandas ancoradas num saber fazer com o corpo; nesse universo o saber do corpo não tem nenhuma chance. Sabemos o que procurar, sabemos como rea- 
gir, estamos prontos! Prontos a responder de acordo com o desejo, a demanda, o saber desenhado pelo outro, ao qual nos alienamos de bom grado para nada termos que saber d'Isso que se passa nesse ponto de abismo que é o corpo quando esse se póe a trabalho.

Talvez "estar presente" seja suportar uma certa dimensão de ausência, estando aberto para esse algo que se coloca em jogo como que para bordejar uma desaparição, revelando ali o residual, jamais passível de ser resgatado, tangível, sendo algo que, na experiência apenas se vislumbra em sua virtualidade (Branco, 1994, p. 34), posto que somos atravessados sem cessar por esse algo que se presentifica na medida em que dele nos separamos, como algo que só existe sob esse ponto de perda, de desvanecimento, de quase-figura...

Para Lacan: "O inconsciente escapa totalmente a este círculo de certezas no qual o homem se reconhece como um eu" (Lacan, 1985 [1954a], p. 15). Dar espaço nesse lugar do corpo para aquilo que aparece sob a condição de seu desaparecimento.

Farejar, tatear no escuro, intuir que ali, naquele invisível, há algo. Para tanto é preciso resistir à compulsão a dar sentido. Dar sentido prematuramente pode significar, não obstante, não escutar.

Do movimento poético sabemos que ele pressupóe o nunca estar inerte com as palavras, com os objetos, com os atravessamentos... Desse modo, penso que nessa escuta faz-se necessário implicar o vazio, esse incognoscível em nós, no processo.

Jacques Alain Miller (2003) relaciona o processo de análise pensado como espaço em que o sujeito se esforça em descrever-se, narrar-se, inventando para si uma história - a um esforço de poesia. A referência à poesia se deve ao fato de que, nesse espaço de análise, suportado por uma situaçáo transferencial, o sujeito poder se dar conta de que tem uma língua própria. Resumidamente, ao falar para um outro, o sujeito se dá conta de sua língua singular - assim como a singularidade de sua via desejante. Entretanto, tal qual a operação poética, essa operação não é simples, posto que pressupóe a descida a um vazio de identificaçóes - ponto em torno do qual a narrativa do sujeito, tecida a partir dessas identificaçôes, se sustenta.

A travessia do fantasma descentra exatamente essa determinação imaginária e significante sobre o sujeito. É nessa travessia que o sujeito terá a oportunidade de dar conta de seu desejo para além dos jogos identificatórios que o constituíram numa aposta sem garantias em seu próprio desejo. 


\section{Via Negativa como Espaço de Travessia}

Voltemos então à Flaszen e sua postulação da vida como matéria-prima do teatro, diferenciando essa da vida que se torna hábito e apontando-a como algo que escapa à tessitura deste. Poderíamos pensar que aqui o hábito se mostra como propulsor de um círculo vicioso com o qual se deve romper para arriscar-se nos territórios do humano, cujo hábito anestesia ou mascara. Desse modo, trata-se de interrogar sobre o corpo e a experiência que dele advém através de um trabalho sobre a memória e, consequentemente, sobre a negatividade do inconsciente, debruçando-nos sobre o que ela tem de inacessível, nuclear, que curiosamente será aquilo que fora não reconhecemos como o nosso mais íntimo.

Podemos pensar, juntamente com Coutinho Jorge, que o que está em jogo nessa construção não é da ordem do esquecimento, pois sabemos que em Grotowski, tal como salienta Lima, não se trata da busca de um resgate dessa memória-arquivo, passível de ser rememorada com o decorrente acesso ao conteúdo esquecido. Trata-se de algo mais próximo de uma operação de recalque, e de um trabalho sobre esses pontos de silêncio, de des-conhecimento. E é o próprio Grotowski que nos dá essa pista ao configurar seu trabalho na vertente de uma via negativa, ou seja, uma via que náo busca adquirir habilidades, mas trabalhar sobre as resistências.

Sobre a diferenciação entre esquecimento e recalque Coutinho Jorge nos alerta que:

A difícil diferença entre esquecimento e recalque é igualmente tematizada por Freud, para quem o recalque tem como modelo o soterramento de Pompéia: "Na verdade não existe melhor analogia para o recalque - que torna algo inacessível e ao mesmo tempo o preserva na mente - do que um sepultamento como o que vitimou Pompéia, e do qual a cidade só pôde surgir pelo trabalho das pás". Lacan, por sua vez, trabalhou a diferença entre esquecimento e recalque postulando que o recalque representa uma espécie de duplo esquecimento: o sujeito náo só esquece, como também esquece que esqueceu (Coutinho Jorge, 2010, p. 41).

De forma que podemos frisar aqui, referente à via negativa, que se trata de um trabalho que tem o inconsciente em seu horizonte de investigação. Sabemos do inconsciente que ele não é o responsável pela resistência, ou seja, ele não resiste, ele insiste. O que resiste é o eu. No dizer de Freud: 
O inconsciente, ou seja, o recalcado, não oferece resistência alguma aos esforços do tratamento. Na verdade, ele próprio não se esforça por outra coisa que não seja irromper através da pressáo que sobre ele pesa, e abrir seu caminho à consciência ou a uma descarga por meio de uma ação real (Freud, 1920, p. 30).

De forma que podemos entender melhor a relação apontada por Lima entre o trabalho sobre si, que inclui um trabalho sobre a memória - sobre aquilo que esquecemos sem saber que esquecemos e, por conseguinte, sobre aquilo que sabemos sem saber que sabemos - e o alargamento de nossa subjetividade, problematizando nessa engrenagem o próprio corpo como ponto a partir do qual um chamado se faz. No dizer da pesquisadora: "Percebemos aqui que não se tratava de debruçar-se sobre uma qualquer memória que fosse importante para o ator, mas de tocar uma certa qualidade da memória capaz de relembrar/criar uma outra percepçáo de/do si mesmo" (2009, p. 5). Desse modo a pesquisadora defende que o trabalho sobre a memória em Grotowski não visa à reprodução no corpo do já conhecido, do já trilhado, ou seja, não se confunde com o rememorar, mas um trabalho ativo de descoberta do desconhecido no corpo.

Tomemos Grotowski:

Quando no teatro se diz: procurem recordar um momento importante da sua vida e o ator se esforça por reconstruir uma recordação, então o corpo-vida está como em letargia, morto, ainda que se mova e fale... É puramente conceitual. Volta-se às recordaçóes, mas o corpo-vida permanece nas trevas. Se permitem que seu corpo procure o que é íntimo [...], nisso há sempre o encontro [...] e então aparece o nós chamamos de impulso (2007 [1970], p. 205-206).

O trabalho de Grotowski parece voltado para aquilo que insiste, persiste como chamado, como uma tentaçáo interior em direção a algo que, desconhecido, ainda assim reclama seus espaços nos tecidos do corpo, apontando caminhos, pequenas luzes. Diz ele: "Há algo que tem que ser feito e está além de você. Até mesmo uma simples evolução nos exercícios corporais - arriscada, dentro de certos limites sem dúvida, e mesmo assim arriscada, com a possibilidade da dor - tudo aquilo que é preciso é não resistir e assumir o risco" (Grotowski, 2007 [1971], p. 174). E ainda: "Não se trata de slogan, mas de algo vivo que é preciso reconfirmar a cada vez" (Grotowski, 2007 [1971], p. 179). 
Arrisco a dizer que o que está em jogo nesse processo de trabalho sobre a memória é de abrir espaço para esse não nascido do qual nos falou Lacan. Parece ser a isso que Flazsen se refere ao afirmar que nesse espaço de passagem, entre as máscaras e a nova máscara do eu não porto nenhuma máscara, algo se produz como um milagre, que o autor nomeia como alguma coisa de vivo que se produz nessa zona de borda e que ele associa, por sua vez, a um nascer de novo, de uma maneira pessoal:

Dentro da partitura do ator, sublinhou Grotowski, anatomista inescrupuloso da arte do ator, não são os desenhos de ação na escala macro, não são as grandes figuras, as atitudes e os gestos, mas as passagens entre eles que são a chave. É ali que corre "o fluxo da vida" e "o fluxo dos impulsos" que fazem com que tudo seja vivo e orgânico (Flaszen, s/d, p. 6, tradução nossa).

Dessa forma, esse não nascido se configuraria como esse algo vivo que é preciso reconfirmar a cada vez. Flazsen ainda salienta que a especialidade de Grotowski era operar:

[...] nessas zonas intermediárias pouco frequentadas, nas passagens. Entre teatro e não teatro; entre a técnica do ator trabalhada em seus detalhes e esse Desconhecido que se abre depois da ultrapassagem da técnica; na passagem de uma história fictícia que é o espetáculo, entre a ilusão e o jogo e a verdade literária confirmada pelo corpo do ator no processo do aqui e agora; na zona intermediária entre o que consideramos como espiritual e corporal, onde essas duas ordens entram em osmose e se interpenetram, onde o corpo do ator torna-se espiritual e o espírito carnal (Flazsen, s/d, p. 6, tradução nossa).

De modo que vale a pena nos indagarmos se no trabalho sobre a memória não se efetiva também nessa zona de opacidade do corpo, quando algo do corpo cai, e que se configura quando mapeamos os efeitos daquilo que, não lembrado, se lembra em nós, como ponto desconhecido a partir do qual um devir se insinua. Um devir-corpo, um devir-homem. 


\section{Notas}

${ }^{1}$ O Real, tal como Lacan o concebe não é o equivalente da realidade. Trata-se daquilo que escapa, daquilo que é estritamente impensável. Este conceito vem subverter a psicanálise, a partir do momento em que instaura a dimensão do impossível como condição do sujeito, ponto de partida e limite para a psicanálise.

${ }^{2}$ Importante salientar que, na teoria psicanalítica, o conceito de desejo náo se alinha à ideia de querer ou necessidade, uma vez que opera articulado ao saber inconsciente, tomado como um saber que não se sabe e que, no entanto, insiste na experiência do sujeito. $\mathrm{O}$ desejo, enquanto tal, está contido na marca da relação com a pulsão, e esta funda-se numa assimetria com o objeto. Ao sujeito é dada a condição da criaçấo, posto que terá de forjar perenemente um objeto que represente a falta radical da disparidade entre a pulsão e seu objeto.

${ }^{3} \mathrm{O}$ Outro, na teoria lacaniana, diz respeito à dimensão simbólica que está na origem da divisão do sujeito.

${ }^{4}$ Os três registros em Lacan são o Real, o Simbólico e o Imaginário que se entrelaçam em nó borromeano. O Imaginário, a partir do qual se constitui o Eu, é o lugar das identificaçóes. O Simbólico é o campo da linguagem, do significante. Este é o Outro que antecede o sujeito, que só se constitui através deste. Ao Real cabe aquilo que resiste a simbolização, "o real é o impossivel", "não cessa de não se inscrever". O Real toca naquilo que no sujeito é resto inassimilável.

${ }^{5}$ Trata-se aqui de pensar, juntamente com Safatle, a negação não restrita simplesmente à indicação de um não-ser, de uma privação, mas um modo de presença do Real, como o que permanece fora da simbolização reflexiva.

\section{Referências}

BENJAMIN, Walter. Magia E Técnica, Arte e Política: ensaios sobre a literatura e história da cultura. São Paulo: Brasiliense, 1994.

BIRMAN, Joel. O Mal-estar na Atualidade: a psicanálise e as novas formas de subjetivação. Rio de Janeiro: Civilização Brasileira, 2007.

BRANCO, Lúcia Castello. A Traiçáo de Penélope. São Paulo: Annablume, 1994.

COSTA, Ana. Corpo e Escrita: relações entre memória e transmissão da experiência. Rio de Janeiro: Relume Dumará, 2001.

FLAZSEN, Ludwik. Au Passage entre les Masques. s/d. (Texto proferido em palestra no Seminário Grotowski em Ouro Preto em 2012 e entregue à pesquisadora pelo autor).

FLASZEN, Ludwik; POLASTRELLI, Carla (Org.). O Teatro Laboratório de Jerzy Grotowski 1959-1969. São Paulo: Fondazione Pontedera Teatro/Ediçóes SESCSP/ Perspectiva, 2007 [1967]. P. 113-118. 
FREUD, Sigmund. Construçóes em Análise. In: Obras Completas ESB. Rio de Janeiro: Imago, 1974 [1937], v. XXIII. P.271-288.

FREUD, Sigmund. O Inconsciente. In: Obras Completas ESB. Rio de Janeiro: Imago, 1969 [1915], v, XIV. P. $171-222$.

FREUD, Sigmund. Recordar, Repetir, Elaborar. In: Obras Completas ESB. Rio de Janeiro: Imago, 1969 [1914], v. XII. P. 159-172.

FREUD, Sigmund. Além do Princípio do Prazer. In: Obras Completas ESB. Rio de Janeiro: Imago, 1969 [1920], v. XVIII. P. 11-76.

FREUD, Sigmund. A Pulsão e seus Destinos. In: Obras Completas ESB. Rio de Janeiro: Imago, 1969 [1915], v. XIV. P. 115-144.

GREEN, André. O Trabalho do Negativo. Porto Alegre: Artmed, 2010.

GROTOWSKI, Jerzy. Farsa Misterium. In: FLASZEN, Ludwik; POLASTRELLI, Carla (Org.). O Teatro Laboratório de Jerzy Grotowski 1959-1969. São Paulo: Fondazione Pontedera Teatro/Ediçôes SESCSP/ Perspectiva, 2007 [1960]. P. 40-47.

GROTOWSKI, Jerzy. Em Busca de um Teatro Pobre. In: FLASZEN, Ludwik; POLASTRELLI, Carla (Org.). O Teatro Laboratório de Jerzy Grotowski 1959-1969. São Paulo: Fondazione Pontedera Teatro/Edições SESCSP/ Perspectiva, 2007 [1965]. P. 105-112.

GROTOWSKI, Jerzy. Exercícios. In: FLASZEN, Ludwik; POLASTRELLI, Carla (Org.). O Teatro Laboratório de Jerzy Grotowski 1959-1969. São Paulo: Fondazione Pontedera Teatro/Ediçóes SESCSP/ Perspectiva, 2007 [1969]. P. 163-180.

GROTOWSKI, Jerzy. O que Foi. In: FLASZEN, Ludwik; POLASTRELLI, Carla (Org.). O Teatro Laboratório de Jerzy Grotowski 1959-1969. São Paulo: Fondazione Pontedera Teatro/Edições SESCSP/ Perspectiva, 2007 [1972]. P. 199-211.

GROTOWSKI, Jerzy. Em Busca de um Teatro Pobre. Rio de Janeiro: Civilizaçăo Brasileira, 1987.

GROTOWSKI, Jerzy. Respuesta a Stanislavski. Máscara: cuaderno iberoamericano de reflexion sobre escenologia, Iztapalapa, México, ano 3, n. 11-12, p. 18-26, 1993.

LACAN, Jacques. O Seminário Livro 20: mais, ainda. Rio de Janeiro: Jorge Zahar, 1985.

LACAN, Jacques. Conferência em Genebra sobre o sintoma. Le Bloc-Notes de la psycanalyse, Paris, n. 5, p. 5-23, 1985 [1975]. Tradução para fins didáticos, feita pelo Campo Psicanalítico de Salvador. Disponível em: $<$ http://www.campopsicanalitico.com.br/biblioteca/genebra.doc $>$. Acesso em: 08 ago. 2010.

LACAN, Jacques. O Seminário Livro 7: a ética na psicanálise. Rio de Janeiro: Jorge Zahar, 1997.

LACAN, Jacques. Do Sujeito enfim em Questão. In: Escritos. Rio de Janeiro: Jorge Zahar, 1998. P. 229-237.

LACAN, Jacques. O Seminário sobre a Carta Roubada. In: Escritos. Rio de Janeiro: Jorge Zahar, 1998. P. 13-66. 
LACAN, Jacques. O Seminário, Livro 10: a angústia. Rio de Janeiro: Jorge Zahar Editores, 2005 [1963c]. P. 252-265.

LACAN, Jacques. O estádio do espelho como formador da função do eu. In: Escritos. Rio de Janeiro: Jorge Zahar Editores, 1998 [1949]. P. 96-103.

LACAN, Jacques. O Seminário, Livro 11: os quatro conceitos fundamentais da psicanálise. Rio de Janeiro: Jorge Zahar Editores, 1998 [1964a]. P. 23-32.

LACAN, Jacques. O Seminário, Livro 2: o eu na teoria de Freud e na técnica da psicanálise. Rio de Janeiro: Jorge Zahar Editores, 1985 [1954a]. P. 9-21.

LIMA, Tatiana Motta. Palavras Praticadas: o percurso artístico de Jerzy Grotowski entre os anos de 1959-1974. São Paulo: Perspectiva, 2012.

LIMA, Tatiana Motta. Resistência e Criação. Jornal Estado de Minas, Belo Horizonte, p. 4, 30 abr. 2011.

LIMA, Tatiana Motta. A Noção de Escuta: afeto, exemplos e reflexóes. ILINX Revista do Lume, Campinas, v. 2, p. 1-19, nov. 2012.

MILLER, Jacques Alain. Um Esforço de Poesia. Opção Lacaniana III: Revista Brasileira Internacional de Psicanálise, n. 5, p. 1-8, mar. 2008.

KEHL, Maria Rita. O tempo e o Cão. A atualidade das depressóes. São Paulo: Boitempo, 2009.

SAFATLE, Vladimir. A Paixáo do Negativo: Lacan e a dialética. São Paulo: Editora UNESP, 2006.

Carla Andréa Lima é doutora em Artes pela Universidade Federal de Minas Gerais (UFMG), mestre em Artes pela UFMG (2007) e graduada em Artes Cências pela UFMG (2004). Coordenadora do Grupo Litura: mapeamentos poéticos do corpoafeto. Psicanalista em formação pelo Círculo Psicanalítico de Minas Gerais. Foi professora substituta de teatro, na área de Direção Teatral e Preparação Corporal do Curso de Teatro da Universidade Federal de Minas Gerais.

E-mail: carlanormagna@gmail.com

Recebido em 08 de novembro de 2012 Aprovado em 10 de dezembro de 2012 